\title{
MOLECULAR COMPOSITION OF COAL LIQUID OIL CHARACTERIZED BY GAS CHROMATOGRAPHY WITH ATOMIC EMMISION DETECTOR
}

\author{
Yusnitati dan Sri Djangkung Sumbogo Murti \\ Pusat Teknologi Pengembangan Sumberdaya Energi \\ BPPT Gedung II lantai 22, JI. MH Thamrin No. 810340 \\ E-mail: sumbogomurti@yahoo.com
}

\begin{abstract}
Heteroatom-containing species in the coal liquid oils (CLO) were identified and quantified by the aid of gas chromatography with atomic emission detector (GC$A E D$ ). Four different CLOs from different rank coals, processes and cut points were investigated in the present study. Thiophene and its derivatives were found to be the major sulfur compounds, pyridines and anilines, and phenols were the major nitrogen and oxygen compounds, respectively in the oils of boiling range $<300{ }^{\circ} \mathrm{C}$. An oil of boiling range $\left(300-420^{\circ} \mathrm{C}\right)$ carried more dimethyldibenzothiophenes and benzoquinolines. The correlation between feed coal and liquid product was discussed in terms of the compositions of heteroatomic compounds.
\end{abstract}

Kata kunci: coal liquid oil, heteroatomic compounds, GC-AED

\section{INTRODUCTION}

Coal liquefaction has been expected to supply liquid transportation fuels to moderate the indispensable dependence on the petroleum products since the supply of crude oil may not meet the increasing demand in near future (Mochida, I.,et al, 1998). Coal liquid oil (CLO) of gas oil fraction tends to carry more heteroatoms such as sulfur, nitrogen and oxygen than the corresponding petroleum product (Yanai, S. et al., 1998). Higher content of such heteroatoms causes serious problems to produce the pollutants, and to cause the poor stability in storage. Furthermore, they may play as inhibitor and poison in the catalytic refining processes, where molybdenum or tungsten sulfide promoted by cobalt or nickel supported on alumina or silica alumina have been usually applied as catalyst (Albro, T. G.,1993; Dorbon, M.,1984; Fathoni, A.,1992; Schmichitter, J. M.,1979).

It is very necessary to quantify the heteroatom-containing molecular species in the coal liquids to clarify their chemical roles and behaviors in the hydrotreatment. Molecular level analyses of sulfur species in gas oil and their reactivity have been reported (Whitehurst,D.D., 1998). Although GC-MS can be applied to measure all species, identification of all molecular species is very tedious.

The present study reports the distribution of heteroatom containing compounds (sulfur, nitrogen and oxygen) in CLOs by the aid of gas chromatography equipped with atomic emission detector (GC-AED). AED is a multi-element detector that can measure more than 20 elements (Albro, T. G., 1993; Quimby, V., 1993). Recently it has been applied to the quantitative analyses of sulfur, nitrogen compounds in gas oil and metal containing compounds in vacuum gas oil. Molecular distribution of heteroatom species may reflect compositional characteristic of starting coal, efficiency of liquefaction process for heteroatom removal, and their cutting point.

\section{EXPERIMENTAL}

\subsection{Coal Liquids Sample}

Crude liquid oils used in this study were supplied from liquefaction pilot plants in Japan, using 4 coals as listed in Table1. Analyses of 4 raw coals are summarized in Table 2. Basic and non-basic fractions of SBCL-B were separated by acid extraction.

\subsection{Gas Chromatography with Atomic Emission Detector}

The identification of heteroatom containing compounds in the CLO was carried out using a HP 6890 with split/splitless injector port gas chromatograph (GC) with a HP G2350A atomic emission detector (AED) system. The chromatographic separation was done on a $30 \mathrm{~m}$ HP-1MS 0.32 internal diameter capillary column with film thickness of $1.0 \mu \mathrm{m}(\mathrm{HP})$. 
Carbon, sulfur, nitrogen and oxygen atomic emissions at 179, 181, 174 and $171 \mathrm{~nm}$ were used to obtained the high selectivity. Two injections of $1 \mu \mathrm{l}$ were carried out with every sample. The first injection was for determination of carbon, sulfur, nitrogen, while the second one was for oxygen. Hydrogen was used for the major reagent gas for both analyses. Oxygen and pure methane was added for the former analyses while $10 \%$ methane in nitrogen was for latter analyses. The HP AED ChemStation was used to control the GC-AED and to perform the data acquisition and peak integration.

\section{RESULTS}

Figure 1 shows the carbon, sulfur, nitrogen, and oxygen chromatograms of SBCL measured by GC-AED. Thiophenes, and dibenzothiophenes derivatives were the major compound identified in the SBCL. Pyridines, aniline and phenols and their derivatives were nitrogen and oxygen compounds respectively.

The carbon chromatograms from 4 CLOs are shown in Figure 2. The sample contained paraffinic hydrocarbon up to $\mathrm{C} 17$ for SBCL-A because of its end point of $300{ }^{\circ} \mathrm{C}$, and $\mathrm{C} 12$ for the others of cutting point of $260^{\circ} \mathrm{C}$. $\mathrm{C} 9$ and $\mathrm{C} 10$ were found to be the highest peak found in the tatter samples. Chromatograms of sulfur compounds in coal liquid distillates are illustrated in Figure 3. The sulfur species observed in CLOs were mostly thiophene and alkyl-substituted thiophenes. Thiophene content in SBCL-A was relatively small compared to those of the others three CLOs. Benzothiophene and its derivatives appeared in SBCL-A at longer retention times corresponding to their higher boiling points. Figure 4 illustrates the nitrogen chromatograms. The nitrogen components identified in CLO were mostly pyridine, aniline and their derivatives. Quinoline, indole and alkyl-substituted indoles were found only in SBCL.

The chromatograms of oxygen species in coal liquid distillates are illustrated in Figure 5. Phenols and alkyl-substituted phenols were the major oxygen compounds found in CLOs, although dibenzofuran was identified only in SBCL-A.

Chromatograms of SBCL-B are illustrated in Figure 6,7 and 8 for carbon (hydrocarbon), sulfur and nitrogen, respectively. SBHD contained paraffinic hydrocarbon of $\mathrm{C} 17$ to $\mathrm{C} 29$. Dibenzothiophene (DBT) and its derivatives were found as major sulfur species. Basic nitrogen species identified in SBHD are mostly aniline, quinoline, benzoquinoline and their derivatives.

\section{DISCUSSION}

GC-AED was confirm to be able to identify basically all molecular species in CLO of boiling range up to $420{ }^{\circ} \mathrm{C}$. The content and distribution of heteroatoms containing species in CLOs appear to reflect the liquefaction process, rank of feed coals as well as boiling range although very similar species were usually contained. Sulfur levels of South Banko, Adaro, and Ikeshima oils were much the same around $0.1 \mathrm{wt} \%$ except for Tanitoharum, although the contents of sulfur in the raw coals were significantly different. The distributions of sulfur species in the former three oils are different. SB carried dimethyl, trimethyl $\mathrm{BT}$ and dibenzothiophene in the boiling range < $300^{\circ} \mathrm{C}$, while Adaro and Ikeshima oils did not carryed. TH oil carried similar species to those of Adaro and Ikeshima, although the sulfur level of the former oil was certainly less than the latter oils. Major difference was observed in the content of thiophene.

Nitrogen content appears more different in oils. The CLO carried nitrogen of $0.4-0.9 \mathrm{wt} \%$, which was much larger than Sulfur. The CLOs of the same boiling range appear to carry the respective nitrogen content, which reflected the contents of the raw coals. The distribution of nitrogen species in the four oils is similar although SB carried quinoline and indoles due to the higher boiling range. TH oil carries more aniline, methyl and dimethylanilines compared to others.

Oxygen contents in CLO reflected the oxygen contents in the starting feeds. CLO carried oxygen of $1-3.7$ wt $\%$, which was the largest heteroatom found. SB of the highest oxygen content produced the much oxygen compound in the oil. The three feed shows the similar content. During liquefaction processing, most of oxygen were found phenols. Dibenzofuran believed to be refractory oxygen species was found only in SB.

The representative aromatic and nonaromatic fraction of SBHD as illustrated in Figure 6 , were clearly separated according to the standard procedure of ASTM D-2549. The percentages of aromatic and non-aromatic fraction were 82.1 and $17.9 \mathrm{wt} \%$, respectively. It is clear that the humping reflects the aromatic fraction. Overlapped peaks of aromatic, condensed napthenic-aromatic, aromatic olefin and heteroatom species such sulfur, nitrogen and oxygen lead to the humping. Non-aromatic fraction contains a series of normal paraffins.

The higher boiling point of SBCL-B contained much complex heteroatoms and mostly refractory species. 4methyldibenzothiophene (61ppm) and 4,6- 
dimethyl dibenzothiophene (12 ppm) of refractory sulfur species were clearly identified. Benzoquinoline and its derivative also identified as the major nitrogen species. Such complex heteroatom compounds with three or more benzene ring believed to be difficult to remove by catalytic up grading, using conventional commercial catalyst. Inhibitor such oxygen compound and basic nitrogen species in CLOs, forces us to design better catalyst and better process for up-grading such a crude in a current transportation fuel.

\section{CONCLUSIONS}

Gas chromatography with atomic emission detector is very powerful for characterization and identification heteroatom species of whole molecular species in petroleum and coal liquid oil.

Thiophenes, benzothiophene as sulfur compound, pyridine, aniline as nitrogen compounds, phenols as oxygen compound were identified in CLOs of lighter boiling point. Dibenzothiohene, quinoline, indole, dibenzoquinoline, dibenzofuran and their derivatives were only found in SB due to its higher cutting boiling range.

\section{REFERENCES}

Albro, T. G., Dreifuss, P. A. , Wormsbecher, R. F., HRC \& CC 1993, 16, $13-17$

Dorbon, M., Ignatiadis, I., Schmitter, J. M., Arpino, P., Guichon, G., Toulhoat, H. A., Fuel 1984, 63, $565-570$.

Fathoni, A. Z., Batts, B. D. Energy Fuel 1992, 6, $681-693$

Mochida, I., Sakanishi, K., Suzuki, N., Sakurai, M., Tsukui, Y., Kaneko, T., Catalyst Surveys from Japan, 1998, 2, 17-30.

Quimby, V., Giarrocco, J., McCleary, K. A., HRC \& CC 1993, 15, $705-709$

Schmichitter, J. M., Vajta, Z., Arpino, P. J., Advances in Organic Gheochemistry, 1979, Pergamon Press Oxford, 1980, 67 - 76

Whitehurst,D.D; Isoda, T.; Mochida,I. Adv.Catal.1998,42,345-471

Yanai, S., Komatsu, N., Shimasaki, K., proceeding, The $6^{\text {th }}$ Japan - China Symposium on Coal and C1 Chemistry, Miyagi, Japan, 1998, 196 - 199 